\title{
ANÁLISE DAS MANIFESTAÇÕES PATOLÓGICAS DE UMA EDIFICAÇÃO DE INTERESSE HISTÓRICO E CULTURAL LOCALIZADA NO VALE DO PARANHANA/RS
}

\author{
BOHRER, CHAIANE \\ Profissão: Acadêmica \\ Instituição: Universidade Feevale \\ Rio Grande do Sul, Brasil. \\ e-mail: chaiabohrer@hotmail.com \\ NADALON, JOSÉ ERNESTO \\ Profissão: Professor \\ Instituição: Universidade Feevale \\ Rio Grande do Sul, Brasil. \\ e-mail: prof_ernesto@feevale.br
}

\author{
ARNOLD, DAIANA \\ Profissão: Professora \\ Instituição: Universidade Feevale \\ Rio Grande do Sul, Brasil. \\ e-mail: daim@feevale.br \\ ORTOLAN, VINICIUS \\ Profissão: Professor \\ Instituição: Universidade Feevale \\ Rio Grande do Sul, Brasil. \\ e-mail: viniciusortolan@feevale.br
}

\section{RESUMO}

O patrimônio histórico que faz parte da história das cidades é essencial para a cultura das pessoas e as construções antigas representam o respeito dos cidadãos com a história. Contudo sua preservação muitas vezes é negligenciada. A fim de manter conservada a história da população local, as edificações históricas necessitam ser conservadas, minimizando o efeito do tempo. Com o intuito de monitorar as degradações, este estudo identificou as manifestações patológicas em uma edificação de interesse histórico e cultural. Foram realizadas visitas à edificação para a identificação das manifestações patológicas presentes, sendo possível com isso apontar suas causas e possíveis soluções. Dentre as situações verificadas, observou-se que a umidade foi a degradação de maior incidência. A análise de corpos de prova retiradas do local permitiu quantificar o teor de umidade, onde verificou-se que os danos causados pela ação da água são decorrentes a umidade ascendente, pois se concentram em regiões próximas ao solo. Apontou-se ainda que na altura de $150 \mathrm{~cm}$ não há concentrações umidade que caracteriza deterioração por umidade ascendente.

Palavras-chave: Manifestações patológicas; Umidade ascendente; Patrimônio Histórico e Cultural.

\section{ABSTRACT}

Historical heritage is part of the history of cities, is essential for people's culture, old buildings show the respect of citizens with history, but their preservation is often overlooked. Historical buildings need to be conserved in order to monitor degradation in order to maintain the population's history. The study identified the pathological manifestations in a building of historical and cultural interest. Visits were made in the building with identification of the pathological manifestations present and pointed out the causes and possible solutions. It is observed that the humidity was the degradation of higher incidence. Specimens were removed to quantify the moisture content, it was found that the damage caused by the action of water is due to rising humidity, because they are concentrated in regions close to the ground and it was also pointed that at a height of $150 \mathrm{~cm}$. There are moisture concentrations that characterize deterioration by rising humidity.

Keywords: Pathological manifestations; Rising humidity; Historical and Cultural Heritage.

\section{INTRODUÇÃO}

O estudo do Patrimônio Cultural Histórico estimula em crianças e adultos um processo ativo de conhecimento, apropriação e valorização de sua herança cultural, a partir da experiência e do contato direto com as evidências e manifestações da cultura em seus múltiplos aspectos, sentidos e significados. A falta de preservação do patrimônio histórico acarreta, muitas vezes, em danos irreversíveis para as edificações levando as mesmas a ruínas. Esta é uma realidade presente nas edificações antigas e, se faz necessário conhecer as manifestações patológicas que levam, muitas vezes, as edificações à degradação, para propor o controle e assim promover a preservação do patrimônio edificado de interesse cultural (HORTA, GRUNBERG e MONTEIRO 2006).

Preservar significa restaurar e conservar a história dos antepassados, que nesta época não se preocupavam com conservação, não tinham dúvidas quando o fato era demolir um patrimônio histórico, logo já aproveitavam o espaço para construir uma nova edificação, buscando maior lucratividade para a localidade. Tudo muda quando surge um novo olhar para o conceito de conservação, onde a população percebe que a história é fundamental para o desenvolvimento das cidades, e que o patrimônio histórico retrata as lembranças da civilização que residiu na localidade (STOLZ et al.2009). 
A preservação do patrimônio histórico e cultural teve destaque no Brasil no ano de 1930, época que foi criado o Instituto de Patrimônio Histórico Artístico Nacional - IPHAN e tornado público o Decreto Lei no 25, de 30 de novembro de 1937 , chamado como Lei do Tombamento Histórico (OLIVEIRA, 2011). A preservação do patrimônio histórico procura conservar as memórias antigas, dando importância a relações sociais presentes em quaisquer circunstâncias. Não é possível conservar as lembranças de uma sociedade, sem preservar a história do seu viver. A conservação do patrimônio deve ter por objetivo preservar os traços de vida diária, e, cada detalhe construtivo leva a entender e demonstrar o dia a dia de uma antiga época, o que é preservado deve ser tratado como valioso, a sociedade conserva as lembranças e a existência da história (ROSIN, 2012). Para preservação do patrimônio cultural edificado, é essencial o apoio das lembranças da sociedade, é fundamental explorar os métodos construtivos e os materiais utilizados na época de sua construção, e a todo momento cuidar a semelhança da construção antiga e da restaurada (FIGUEIREDO, 2014).

Segundo Klüppel (2010), o proprietário de um imóvel de patrimônio histórico deve lembrar sempre que sua construção é parte importante da história e cultura de sua cidade. Ter um imóvel antigo é sempre um privilegio, é ser dono de uma parte da história do Brasil. Portanto, ajudando na preservação desse tipo de edificação, até mesmo com alguma reforma ou procedimento de limpeza e manutenções durante a vida útil do imóvel, é possível para sua conservação, afim de impedir a ocorrência de danos.

Após breve explanação sobre a importância da conservação do patrimônio histórico e cultural, este trabalho tem como objetivos analisar as manifestações patológicas de uma edificação de patrimônio histórico e cultural localizada no vale do Paranhana, realizar levantamento e mapeamento das manifestações patológicas existentes na edificação, assim como, identificar a manifestação patológica de maior incidência e realizar ensaios laboratoriais para comprovar a veracidade da informação.

Critérios importantes de análises, métodos de inspeção e classificação das manifestações patológicas em edificações de interesse histórico foram descritor por .Mesquita (2015) no qual elenca abordagens que permitem desde o levantamento de manifestações patológicas, passando pela tomada de medidas para reestabelecer as funções do elemente que sofreu degradação e chegando até a análise de compromentimento estrutural da edificação. Lourenço (2013) apresenta alguns cases, em que expõe aplicações de metodologias para investigação e solução das manifestações patolígicas. Os autores discutem ainda na complexidade de algumas intervenções e da gama de ensaios que atuam de forma complementar na determinação de soluções para a conservação das edificações.

A importância deste estudo está na identificação das manifestações patológicas com o intuito de promover discussões sobre melhorias de conservação do patrimônio histórico e cultural, visando a preservação das edificações de interesse histórico.Segundo Antunes (2010), é cada vez maior o número de incidências de manifestações patológicas em edificações históricas com origens diversas, os prédios antigos são abandonados e ficam sem manutenção num grande período, com isso, acarreta um grande número de manifestações patológicas nas construções antigas.

\section{MÉTODOLOGIA}

O método utilizado para desenvolver o presente trabalho busca levantamento global da real situação interna e externa do imóvel de patrimônio histórico e cultural, no que se refere às manifestações patológicas.

O objeto de estudo consite em uma edificação de valor histórico e cultural, sendo a edificação mais antiga ainda existente na cidade, localizado no Vale do Paranhana/RS. O sistema construtivo da edificação, prioritariamente é em alvenaria de tijolos maciços e revestimento em argamassa contendo cal, as vedações verticais apresentam dimensões aproximadas de $20 \mathrm{~cm}$ de espessura, sendo edificado na segunda metade do século XIX, precisamente no ano de 1882, totalizando a área total de $1.490,00 \mathrm{~m}^{2}$ construido. Salienta-se a grande incidência de desplacamentos do revestimento na edificação demonstrando claramente a falta de manutenções e preservação do ambiente analisado. Segundo Wilimzig et al. (2014), em sua construção, utilizou-se pó das conchas marinhas como agregado miúdo na execução da argamassa de assentamento dos tijolos maciços, confeccionados artesanalmente.

A edificação encontra-se, atualmente desocupada, tendo sido construída para abrigar um comércio de tecidos, roupas e ferragens, sendo o ponto mais movimentado pelos viajantes, na época, pois situa-se próximo à estação ferroviária.

O prédio de interesse histórico em questão (Figura 1) é tombado como patrimônio histórico pela prefeitura, seu tombamento foi oficializado em 13 de agosto de 2012. A prefeitura da cidade estuda um projeto de revitalização da edificação, destinando a utilização do imóvel para um museu, um arquivo histórico, uma biblioteca pública e uma sala multiuso de apoio à estas funções (WILIMZIG et al. 2014). 


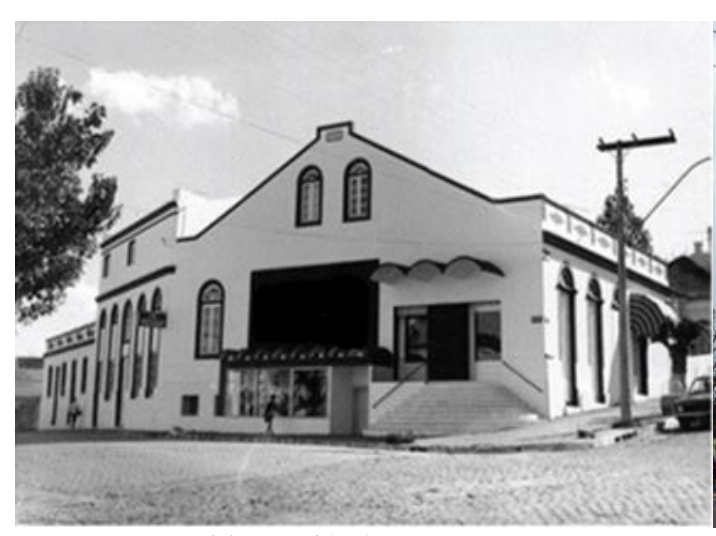

(a) Em 1969

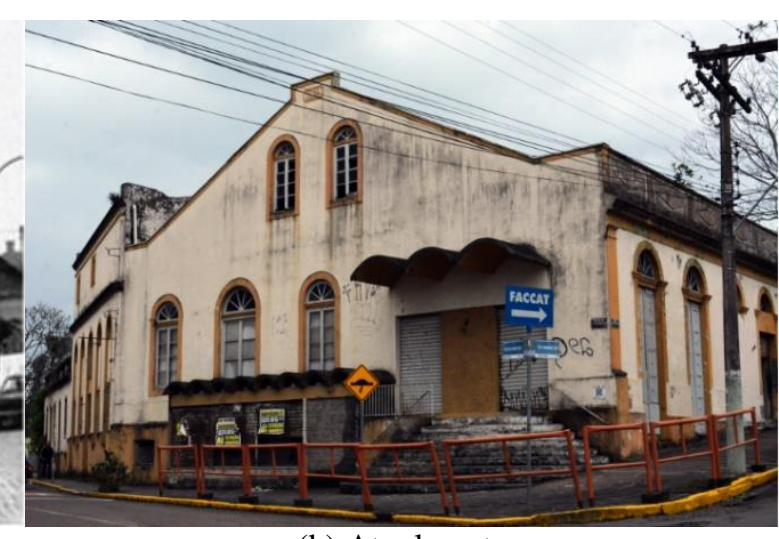

(b) Atualmente

Figura 1: Fachada da edificação

A Figura 1 demonstra as fachadas da edificação. Na Figura 1(a), percebe-se a fachada após a primeira reforma ocorrida no ano de 1969. A Figura 1(b) representa a situação atual da edificação, sem cuidados, sendo alvo de vandalismo.

\subsection{Inspeção do local}

Foram realizadas inspeções na edificação em estudo para coleta de informações. As inspeções ocorreram com o intuito de analisar e conhecer os ambientes que compõem a edificação, onde estão localizadas uma série de manifestações patológicas com intensidade e características variadas. Além de realizar levantamentos fotográficos e mapeamento dos locais com incidência de manifestações patológicas. Ainda assim, foi possível fazer a retirada corpos de prova a fim de identificar o teor de umidade dos elementos construtivos.

Limitou-se em fotografar os locais onde havia maior incidência de anomalias na edificação, onde se encontravam os pontos considerados mais críticos em relação a degradação da mesma, localizados no sistema de vedação vertical de alvenaria e nos elementos estruturais em madeira.

As manifestações patológicas existentes na edificação foram mapeadas, localizadas em planta baixa e identificadas por cores. Como foram identificados diferentes tipos de manifestações patológicas na edificação, elaborou-se um modelo de ficha com o intuito de catalogar as manifestações patológicas existentes no ambiente interno e externo da edificação, conforme apresentado no Figura 2, contendo informações sobre a manifestação patológica identificada, registros fotográficos, sua localização na planta baixa, análise e diagnóstico do dano.

\begin{tabular}{|l|l|}
\hline \multicolumn{2}{|c|}{ FICHA DE IDENTIFICAÇÃO DA S MANIFESTAÇõES PATOLÓGICAS } \\
\hline MANIFESTAÇÄO PATOLÓGICA: & $\begin{array}{c}\text { PLANTA BAIXA: } \\
\text { Imagem do local }\end{array}$ \\
\hline FOTO: & $\begin{array}{c}\text { Planta baixa desenhada no auto CAD, } \\
\text { idificando o local da manifestação patológica }\end{array}$ \\
Informações da manife stação patológica & Marcar o local da foto na planta baixa \\
\hline ANÁLISE E DIAGNÓSTICO: & \\
\hline
\end{tabular}

Figura 2: Modelo da ficha de identificação das manifestações patológicas

Com a elaboração das fichas de identificação das manifestações patológicas, foi possível apresentar a tipologia com maior incidência, e também, relatar as causas e possíveis soluções para as mesmas. 


\subsection{Análise da manifestação patológica com maior incidência}

Após o levantamento e diagnóstico das manifestações patológicas realizou-se a análise quantitativa em porcentagem através de um gráfico para identificação da manifestação patológica com maior incidência (Figura 6). Partindo deste resultado, foram realizadas extrações de testemunhos na edificação para análise de comprovação da classificação da manifestação patológica com maior ocorrência.

\subsection{Retirada dos corpos de prova}

Realizou-se a extração de oito amostras de argamassa de assentamento e revestimento em pontos que apresentaram umidade ascendente (manifestação patológica com maior incidência no objeto de estudo) em alturas distintas, para identificação de umidade nos locais analisados. As amostras de argamassa de assentamento aparentemente não contimham cal, porém a argamassa de revestimento apresentou vestígeos da incidência de cal, essas amostras foram coletadas na edificação em 03 de maio de 2019, aproximadamente às 14 horas e 35 minutos, o tempo era de céu nublado, com temperatura de $26^{\circ} \mathrm{C}$, no outono. Na coleta das amostras utilizou-se um martelo, uma furadeira com broca de diâmetro $10 \mathrm{~mm}$, uma talhadeira e recipientes poliméricos limpos. Após a retirada das amostras, ainda no ambiente, foram enumerados e selados todos os recipientes para evitar contaminação e perda de umidade para o ambiente. O material coletado foi a argamassa de revestimento, a Figura 3 demonstra, em planta baixa, os locais de retirada, indicados pela cor azul.
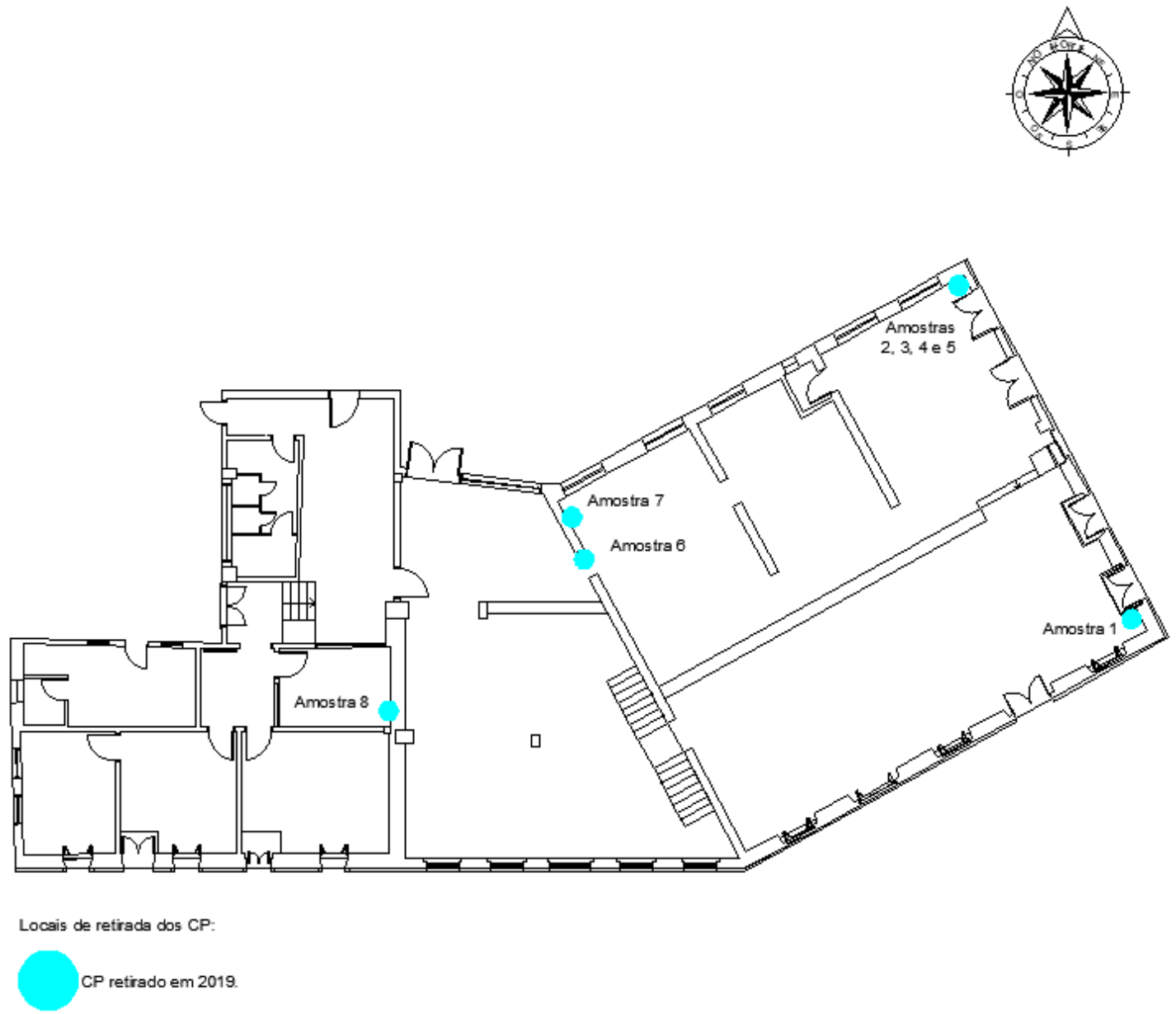

Figura 3: Locais de retirada dos CP's

A intenção da retirada das amostras em alturas diferentes, foi identificar incidência de umidade ascendente na argamassa de revestimento, nas amostras 2, 3, 4, 5 e 8 e no material de revestimento, nas amostras 1, 6 e 7 os pontos demarcados na planta baixa, a fim de confirmar a existência da manifestação patológica de ascensão capilar. Foram selecionadas de forma aleatória as diferentes alturas, afim de demostrar a porcentagem de umidade presente em diferentes alturas da parede. Os pontos amostrados são apresentados nas Figuras 4 e 5, as quais expõem a situação do local de coleta das oito amostras para o ensaio de teor de umidade. 


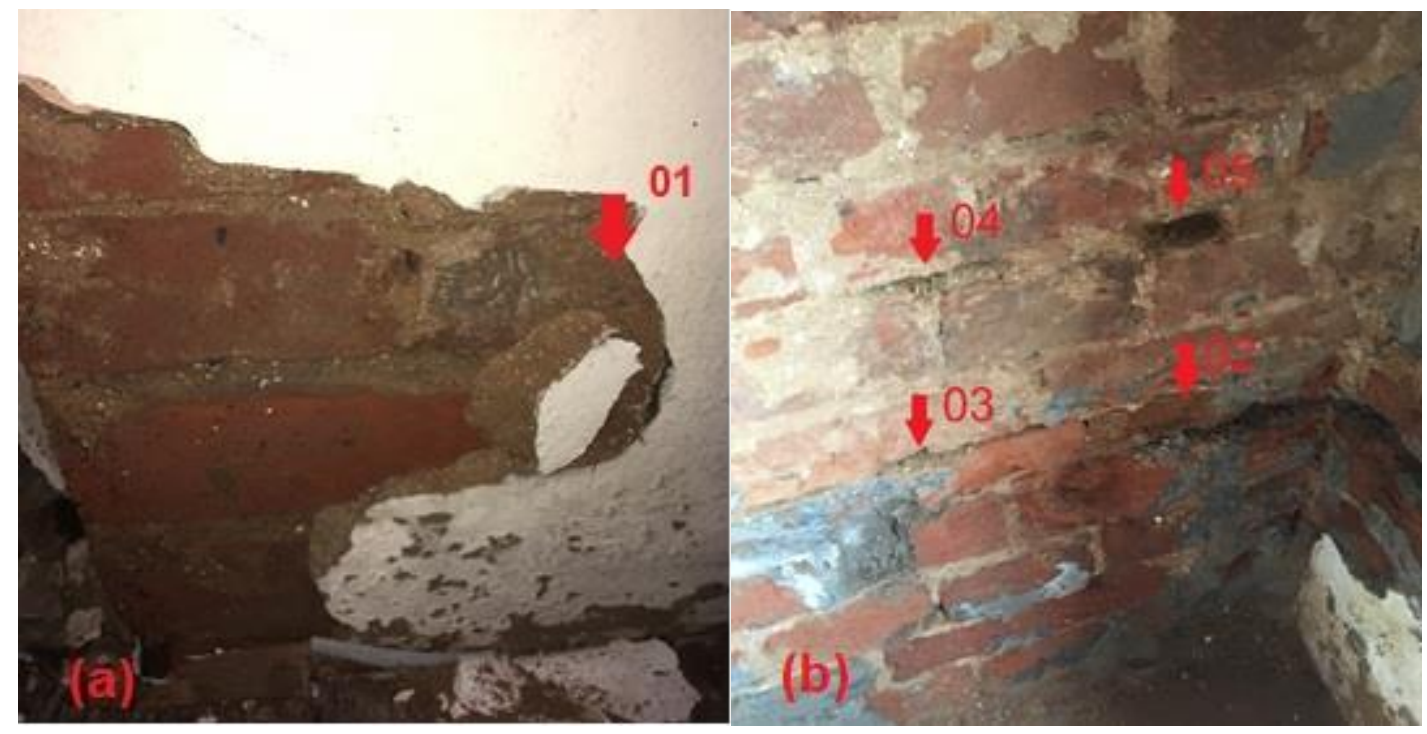

Figura 4: Representação das extrações das amostras

Legenda: (a) Amostra 1, (b) Amostra 2, 3, 4 e 5.

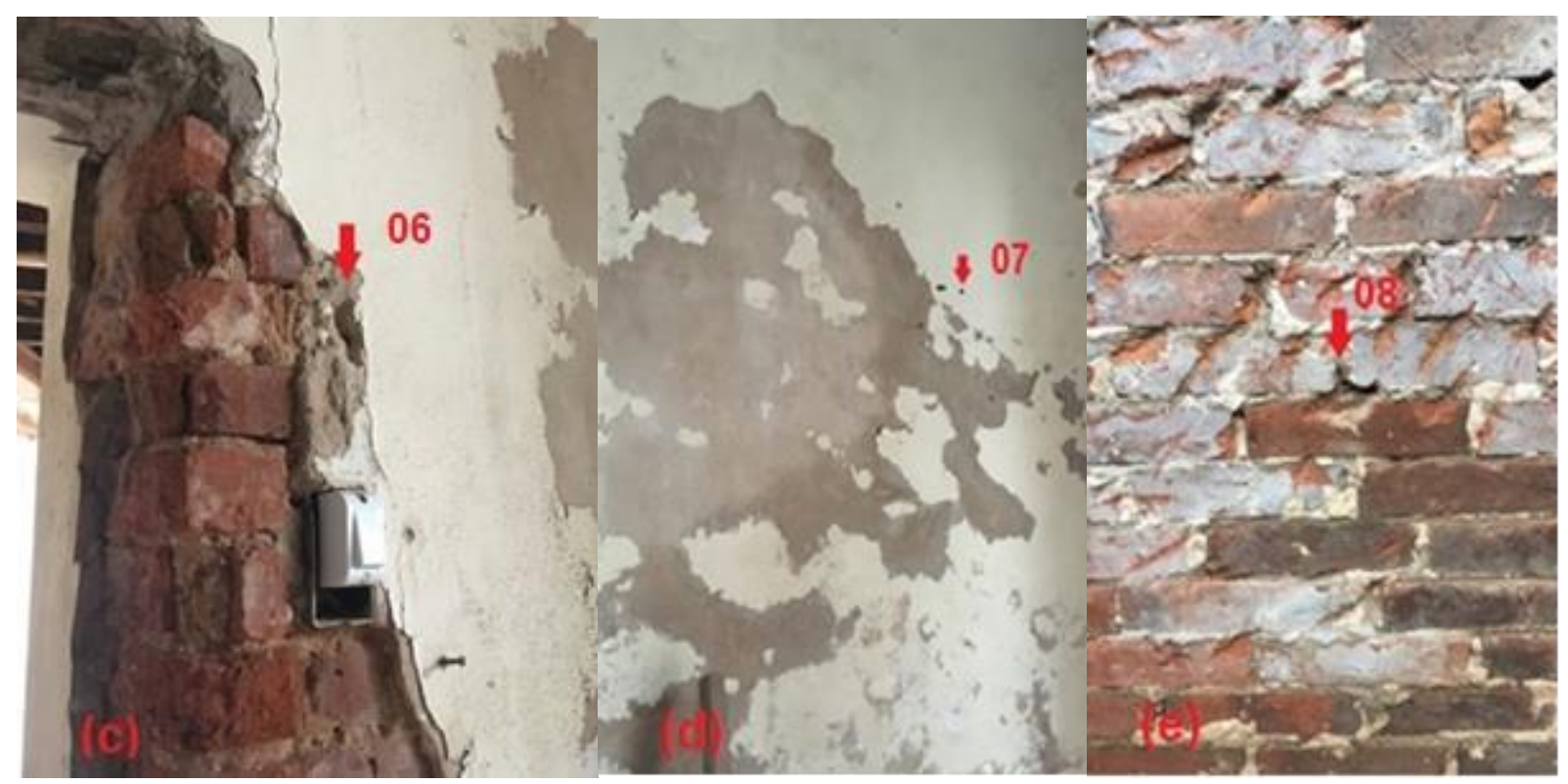

Figura 5: Representação das extrações das amostras

Legenda: (c) Amostra 6, (d) Amostra 7 e (e) Amostra 8.

Na Figura 4(a), local de retirada da Amostra 1, nota-se a presença de umidade na parede, apresentando desplacamento da camada de revestimento e incidência de bolhas na pintura. Na Figura 4(b) local de extração das amostras 2,3,4 e 5, a argamassa de assentamento dos blocos substituída apresentando diferenças de tonalidades. A Figura 5(c) no local de retirada da Amostra 6, pode-se identificar a existência de umidade ocasionando o desplacamento da argamassa de revestimento, assim como fissuras e bolhas na pintura. A Figura 5(d), local da extração da Amostra 7, foi obtida na mesma parede da Amostra 6, onde pode-se perceber as manchas de umidade e descolamento da pintura. A Figura 5(e) representa a extração da Amostra 8, local exposto ao intemperismo, segundo relatos dos profissionais que atuavam na edificação no momento da inspeção, neste local houve a remoção da cobertura pois apresentava risco estrutural. Neste local percebe-se o desplacamento total da camada de revestimento.

\subsection{Ensaios laboratoriais}

Após a extração das 8 amostras, as mesmas foram encaminhadas para a Universidade Feevale para execução dos ensaios no laboratório de Técnicas Construtivas da Universidade, tendo início no dia 03 de maio de 2019, com o objetivo de 
determinar o teor de umidade de cada amostra coletada. A execução do programa experimental seguiu as recomendações da NBR 9778 (ABNT, 2009), utilizando o método de determinação da absorção de água em argamassas como referência.

Foi registrada a massa das cápsulas que foram utilizadas para armazenar as oito amostras. Em seguida, foi registrada a massa de cada cápsula somada a argamassa de revestimento da amostra individualmente, numa balança de precisão com resolução de $0,01 \mathrm{~g}$. Após obter a massa das oito cápsulas, elas foram armazenadas em uma estufa dotada de termostato para garantir uma temperatura de $103^{\circ} \mathrm{C} \pm 2^{\circ} \mathrm{C}$, pelo período de 24 horas. Para resfriamento das amostras, foi utilizado um dessecador, em seguida foram novamente pesadas a fim de obter-se a massa seca da argamassa de revestimento.

\section{RESULTADOS}

Neste capítulo serão apresentados os resultados alcançados, as análises e discussões dos resultados.

\subsection{Seleção da manifestação patológica com maior incidência}

O levantamento de todas as manifestações patológicas encontradas na edificação é apresentado na Figura 6, o percentual foi realizado definindo a incidência, com base no mapeamento, levantamento fotográfico e as relacionado com a bibliografiade cada uma das manifestações patológicas apresentadas na edificação.

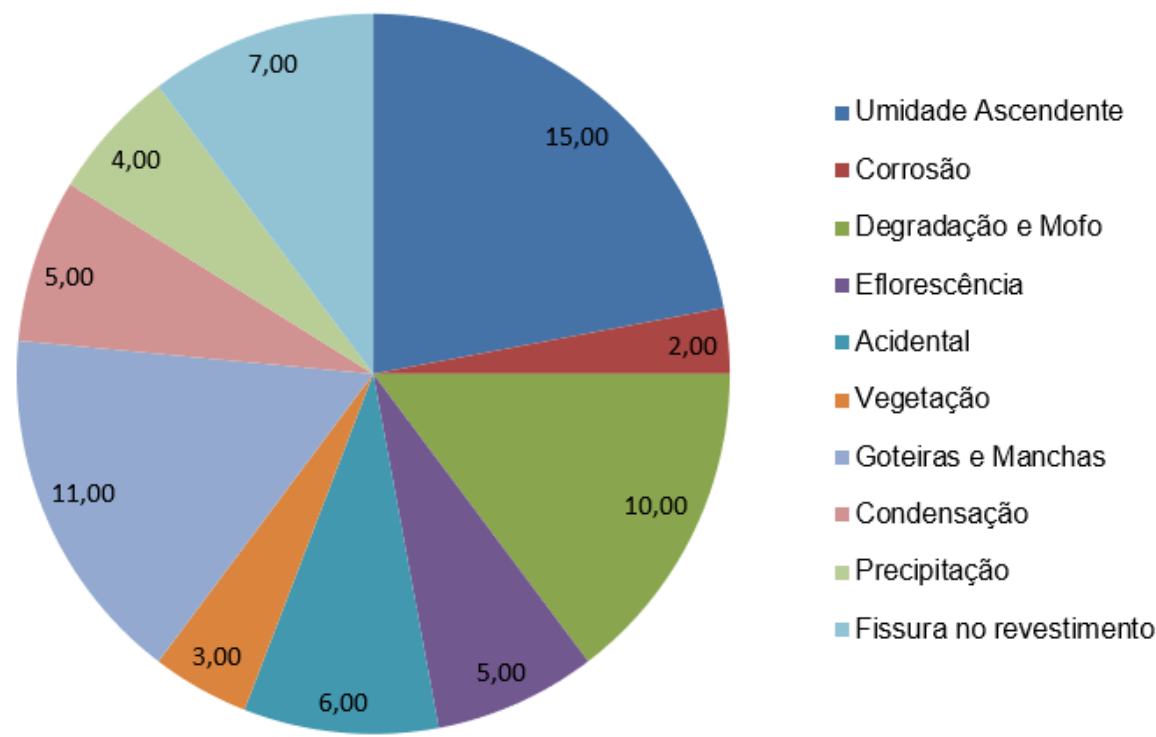

Figura 6: Levantamento das manifestações patológicas

Na Figura 6, observa-se que a manifestação patológica com maior incidência entre as dez manifestações patológicas identificadas foi umidade ascendente, com 15\%. Conforme também analisado por Schönardie (2009), Torres e Silva (2015), e Santos et al. (2013) comprovando que a umidade ascendente está presente em diversas edificações históricas. Para análise laboratorial partiu-se deste resultado para delimitar a proposta da pesquisa. O objetivo dos ensaios de laboratório é confirmar a análise de inspeção visual realizada na edificação.

\subsection{Identificação das manifestações patológicas e diagnóstico das possíveis causas e soluções}

Com base nas fichas de identificação das manifestações patológicas presentes na edificação, descritas no método, foi possível esclarecer suas principais fontes causadoras das patologias e sugestões de solução do dano. A Figura 7 apresenta a Ficha 1 da manifestação patológica identificada como umidade por precipitação. 


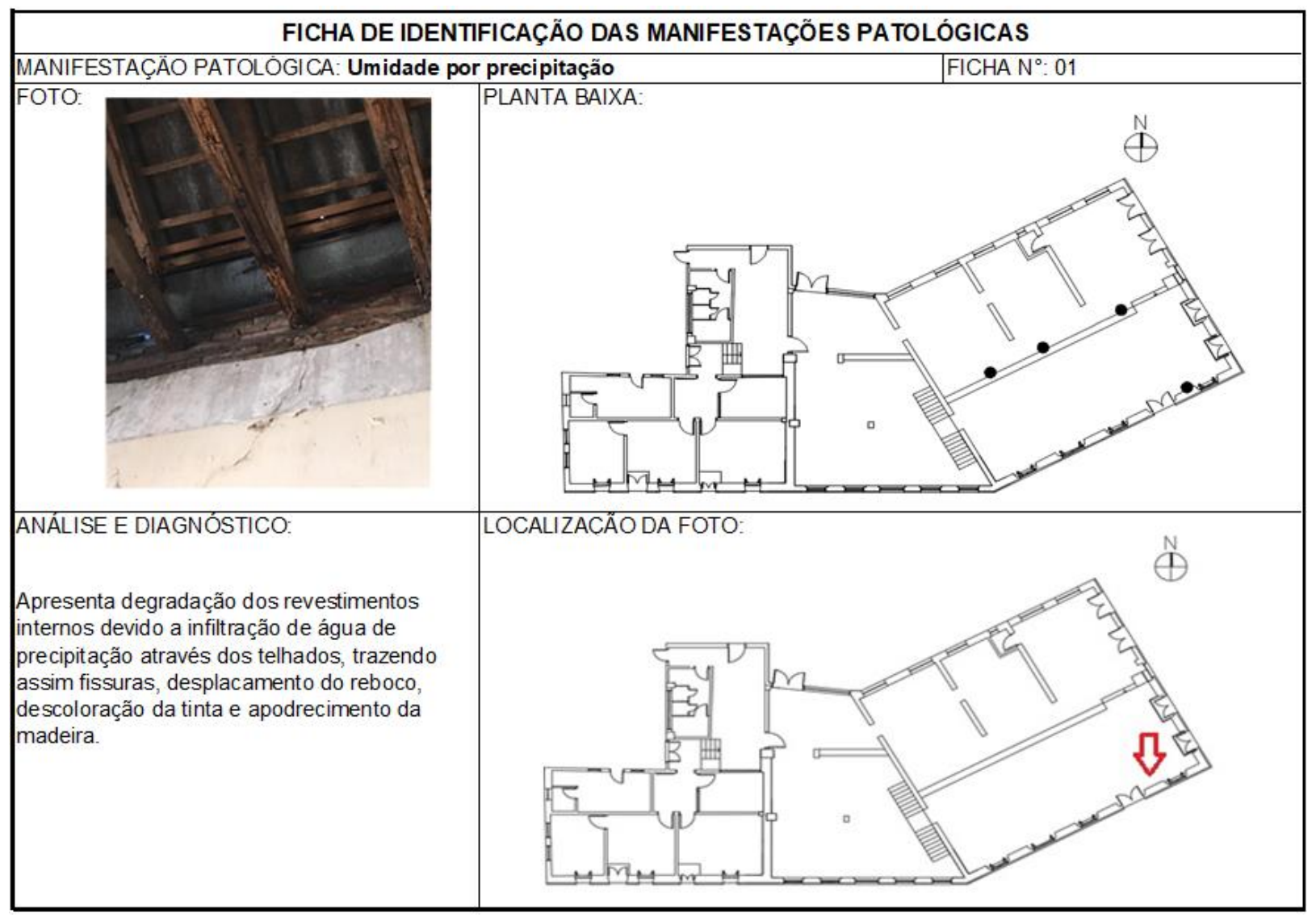

Figura 7: Ficha 1

Na Ficha 1 (Figura 7) estão representados em planta baixa, pela cor preta, os locais de ocorrência desta manifestação patológica de umidade por precipitação. Na foto, visualiza-se manchas na alvenaria de vedação, percebe-se, ainda, que o escoamento da água da chuva ocorre pela alvenaria de vedação, danificando a mesma, bem como o madeiramento estrutural do sistema de cobertura.

\section{- Causas}

Os danos apresentados são decorrentes de frequentes infiltrações oriundas do sistema de cobertura, pelas telhas e calhas. As telhas encontram-se em situações precárias, muito danificadas, assim como as calhas, que além de mal conservadas, há acúmulo de material sobre a mesma, o que dificulta o adequado escoamento da água. Para Souza (2008), as causas dos fenômenos de umidade por precipitação são, geralmente por falhas na manutenção das calhas e no telhado. Concluindo que falta de manutenções no sistema de cobertura, acarreta em manifestações patológicas prejudicando a edificação.

\section{- Soluções}

Acredita-se que para solucionar as manifestações patológicas oriundas da infiltração por precipitação será necessário remoção e substituição total das telhas, limpeza e adequação das calhas. Sugere-se também, a substituição do madeiramento estrutural, impermeabilização, chapisco e novo revestimento argamassado nas alvenarias de vedação, assim como nova pintura. A análise das soluções vem de encontro com os estudos de Silva (2012) onde comenta que, para impedir a infiltração por precipitação recomenda-se uma boa impermeabilização na parte externa das alvenarias de revestimento, bem como, reparos e manutenções nas calhas e no telhado.

Em continuidade a análise de estudo, a Figura 8 apresenta a Ficha 2 da manifestação patológica identificada como umidade de ascensão capilar. 


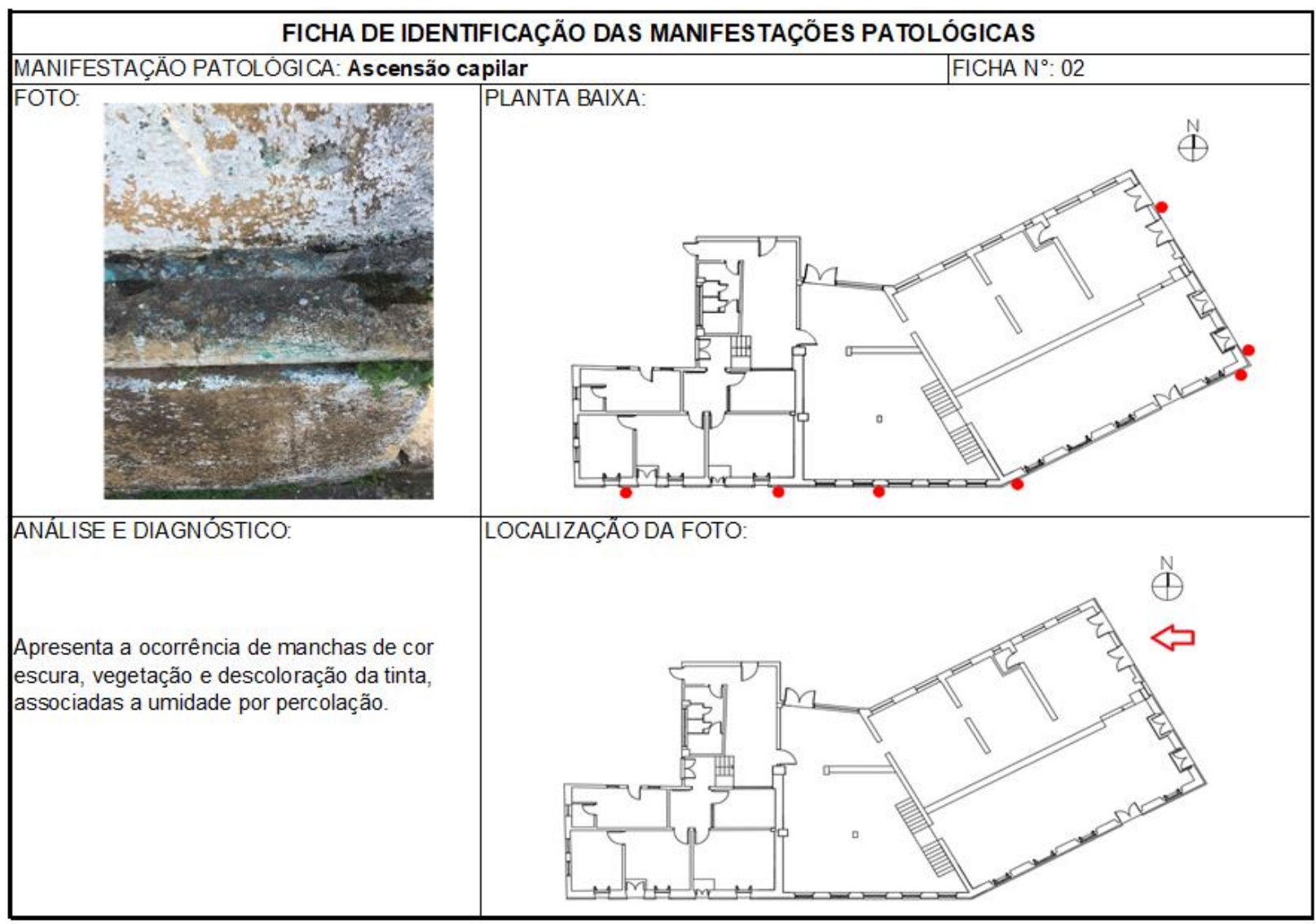

Figura 8: Ficha 2

Na Ficha 2 (Figura 8) estão apresentados na planta baixa, pela cor vermelha, os locais que ocorrem a manifestação patológica de ascensão capilar, pela foto pode-se identificar esta ocorrência na superfície externa da edificação, onde se manifesta através de manchas de vegetação, mofo e degradação na alvenaria de vedação.

\section{- Causas}

As avarias apresentadas anteriormente são recorrentes de falta de impermeabilização, falta de sistema de drenagem, constante presença de umidade e falta de incidência da luz solar. Segundo estudos de Schönardie (2009), o autor confirma as principais causas da ascensão capilar como falta ou falha nos sistemas de impermeabilização das vigas de baldrames, sistemas de drenagem, luz solar e existência de umidade.

\section{- Soluções}

Entende-se que para solucionar as manifestações patológicas recorrentes de ascensão capilar, faz-se necessário remover as partes danificadas do revestimento, a fim de promover nova camada de impermeabilização, chapisco e novo revestimento argamassado nas alvenarias de vedação, assim como nova pintura. Nós estudos de Silva (2012) a adequada solução para ascensão capilar é a promoção de camada de impermeabilização.

Em continuidade ao estudo, a Figura 9 apresenta a Ficha 3 da manifestação patológica identificada como fissuras no revestimento. 


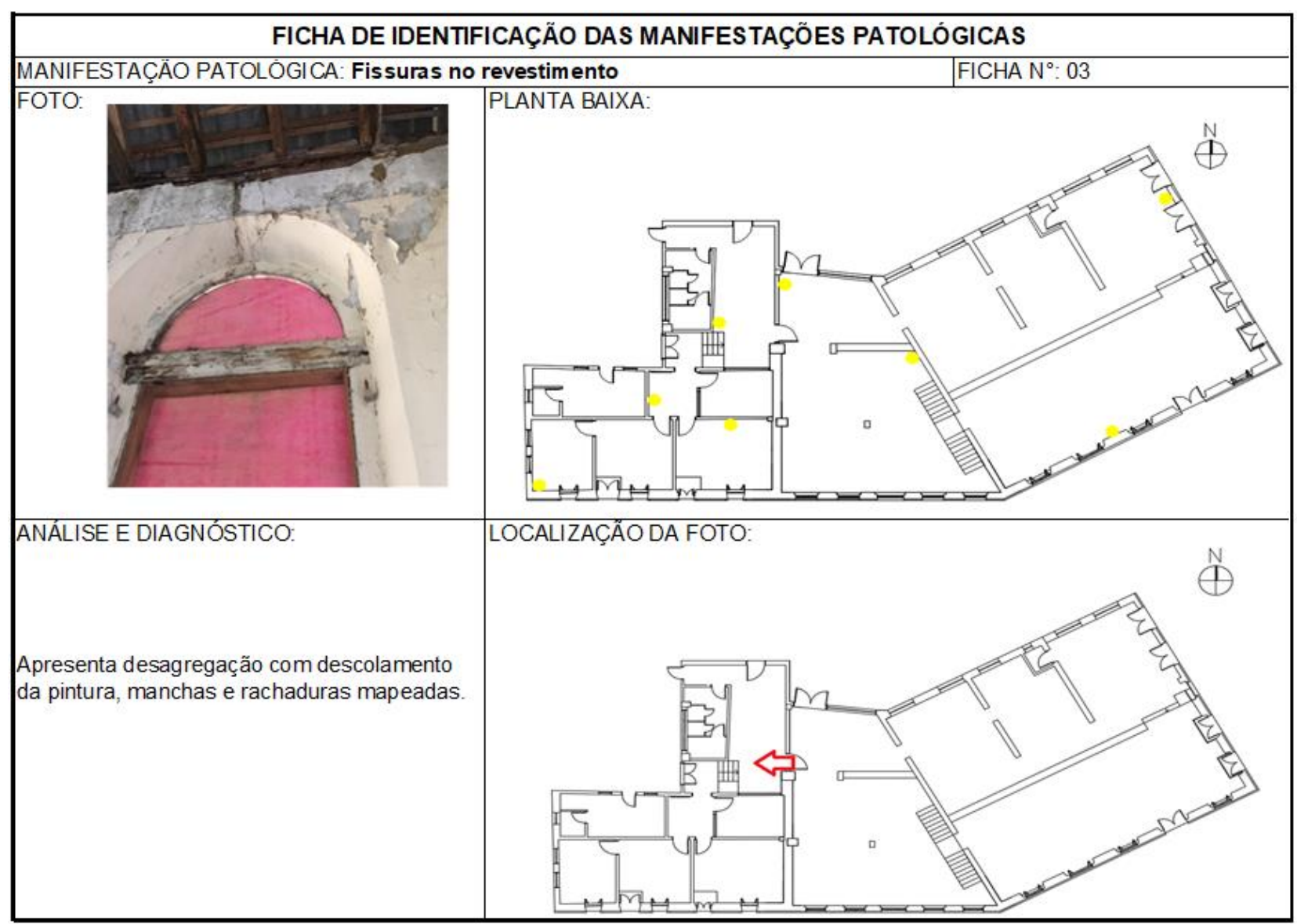

Figura 9: Ficha 3

Na Ficha 3 (Figura 9) estão apresentados na planta baixa, pela cor amarela, os locais onde se encontram a manifestação patológica de fissuras no revestimento. Pela imagem, pode-se visualizar a fissura no revestimento interno da edificação, deterioração na madeira e descolamento da tinta.

\section{- Causas}

Os danos descritos na ficha 3, são ocasionados pela ausência de manutenção no sistema de cobertura, a qual envolve as telhas e calhas. Para Torres e Silva (2015), com as fissuras no revestimento, pode prejudicar a vida útil da edificação, facilitando o aparecimento de novas manifestações patológicas, como degradação do material através de água da chuva ou umidade por infiltração. Geralmente as causas das fissuras são por diferenças nas deformações de tração e retração, que surgem por variação de temperatura, afetando o revestimento das alvenarias de vedação e facilitando no surgimento das fissuras nas partes mais frágeis. Não se registrou-se a orientação ou distribuição da fissura, além de sua profundidade, por consequência da inspeção se dar de forma visual.

\section{- Solução}

Acredita-se que para solucionar a manifestação patológica oriunda de infiltração, faz-se necessário a remoção do revestimento e posterior aplicação de material flexível que acompanha as movimentações da estrutura para ter um excelente fechamento da fissura e facilitando em refazer o revestimento argamassado. Segundo os estudos de Stolz et al. (2009), a solução seria executar novo revestimento, fechar as fissuras com material flexível, onde pode ser usado um selante neutro de silicone. Para Torres e Silva (2015), uma possível solução é remover todo o revestimento onde está fissurado e utilizar argamassa de reparação, produto pronto formulado à base de cimento Portland, agregados classificados, aditivos especiais, polímeros e inibidores de corrosão que, quando misturados, resultam numa argamassa moldável com alta resistência mecânica e com aderência ao concreto da estrutura existente, impedindo a penetração de água, e depois de já ter ocorrido a cura, colocar uma tela, para em seguida refazer o reboco. 


\subsection{Resultados dos ensaios de teor de umidade}

Os resultados do teor de umidade, após a realização dos ensaios em oito amostras de argamassa da edificação em estudo, estão apresentados na Tabela 1 e Figura 10. Pode-se observar a variação do teor de umidade das amostras em relação à altura de extração das mesmas.

Tabela 1 - Resultados do teor de umidade em relação a altura

\begin{tabular}{c|c|c}
\hline $\begin{array}{c}\mathbf{N}^{\circ} \text { das } \\
\text { amostras }\end{array}$ & $\begin{array}{c}\text { Teor de } \\
\text { Úmidade }(\%)\end{array}$ & $\begin{array}{c}\text { Altura } \\
(\mathrm{cm})\end{array}$ \\
\hline 1 & 6,91 & 25 \\
\hline 2 & 11,15 & 15 \\
\hline 3 & 12,30 & 15 \\
\hline 4 & 10,95 & 30 \\
\hline 5 & 10,27 & 30 \\
\hline 6 & 5,47 & 180 \\
\hline 7 & 4,84 & 260 \\
\hline 8 & 1,46 & 170 \\
\hline
\end{tabular}

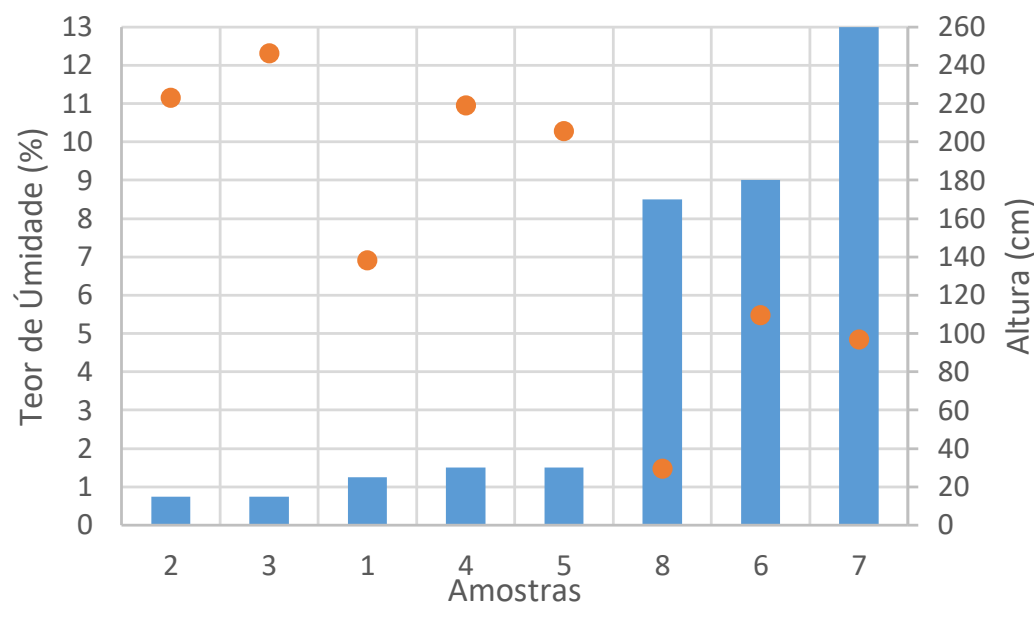

Figura 10: Teor de Úmidade x Altura

A Amostra 1, apresenta um teor de umidade de $6,91 \%$, em uma altura de $25 \mathrm{~cm}$ do piso acabado, pode-se confirmar essa umidade como umidade ascendente, pois está ascendendo do solo.

As Amostras 2 e 3 foram retiradas a $15 \mathrm{~cm}$ de altura em relação ao piso acabado, enquanto que as Amostras 4 e 5 foram retiradas a $30 \mathrm{~cm}$ de altura ao piso acabado. Compreendendo assim o teor de umidade das Amostras 2 e 3 de $11,15 \%$ e 12,30\% e as Amostras 4 e 5 com 10,95\% e 10,27\%, respectivamente, percebe-se diminuição da concentração de umidade, entre estas alturas analisadas, o que pode ser relacionada a variação de altura da retirada das amostras, logo, pode-se confirmar a ocorrência da umidade oriundo do solo por ascensão capilar.

$\mathrm{Na}$ Amostra 6, retirada numa altura de $180 \mathrm{~cm}$ em relação ao piso acabado, observa-se que a porcentagem de umidade foi de $5,47 \%$. Percebe-se que o local de retirada dessa amostra foi numa altura superior as amostras 1,2, 3, 4 e 5 e que ambas obtiveram uma porcentagem maior de umidade.

A Amostra 7, removida a uma altura de $260 \mathrm{~cm}$ em relação ao piso acabado, foi coletada na argamassa de revestimento na parte interna da edificação, com isso, teve uma porcentagem de umidade de 4,84\%, umidade inferior a amostra 6 que foi coletada a uma altura menor.

$\mathrm{Na}$ Amostra 8, retirada a uma altura de $170 \mathrm{~cm}$ em relação ao piso acabado, pode-se observar uma porcentagem de umidade de 1,46\%, ao estudar melhor o local da retirada da amostra, segundo informações adquiridas na coleta das amostras, foi removido o telhado, ficando exposto ao tempo. Com isso, a parede fica exposta ao sol da tarde. Na Figura 6, mostra que essa alvenaria de vedação fica ao oeste da edificação, onde o sol se põe. Com isso pode-se concluir o motivo da perda de porcentagem de umidade. Resende (2000), afirma que para secagem rápida da umidade nas alvenarias de vedação, é só deixá-la exposta as condições climáticas, no sol da tarde (sol mais quente).

Em consequência da quantidade de amostras coletadas, não pode-se carcaterizar o perfil de propagação da umidade ascendete, sugere-se que uma maior quantidade de amostras seram retiradas para então o perfil da asceção da umida possa ser graficado.

A pressão necessária para que a água alcance determinadas alturas ou as alturas analisadas não foi possível quantificar neste trabalho, pelo fato da haver diferentes materiais envolvidas em com tensões superficiais, asism como o raio de contato desconhecidos para este trabalho. 


\section{CONCLUSÕES}

A metodologia de análise permitiu o levantamento das condições atuais da edificação, tornando possível a descrição das formas de degradação presentes nas alvenarias. Após reunir todas as informações das fichas, torno-se evidente que a umidade ascendente foi a manifestação mais frequente, sendo este o foco das análises. Pode-se identificar que a umidade proveniente do solo em todas as amostras, pois o teor de umidade varia conforme a altura da retirada das amostras. Com isso, é capaz de se identificar que quanto mais próximo de $260 \mathrm{~cm}$ for a coleta das amostras menor a porcentagem de umidade na alvenaria de vedação, e quanto mais próxima ao piso acabado maior a porcentagem de umidade. Consequentemente, tem-se que para uma variação de $15 \mathrm{~cm}$ de altura, para as localidades próximas ao solo, em até $30 \mathrm{~cm}$ de altura, a umidade presente diminui em média $1,10 \%$.

Confirmando que para maiores alturas menor a energia de ascensão é insuficiente para alcançar maiores patamares de umidade. Estas análises servirão como norteadoras para agir na solução do problema e também nas ações de restauro e preservação da edificação em estudo.

\section{REFERÊNCIAS}

ASSOCIAÇÃO BRASILEIRA DE NORMAS TÉCNICAS. NBR 9778. Argamassa e concreto endurecidos Determinação da absorção de água, índice de vazios e massa específica. Rio de Janeiro, 2009.

ANTUNES, G. R. Estudo de manifestações patológicas em revestimento de fachadas em Brasília - Sistematização da incidência de caos. Dissertação (Mestrado em Estruturas e Construção Civil). 178 f. Universidade de Brasília, Brasília, 2010.

GOOGLE EARTH. Taquara/RS. Acesso em: 17 set. 2019.

HORTA, M. L. P., GRUNBERG, E., MONTEIRO, A. Q. Guia Básico de Educação Patrimonial. Brasília: Instituto do Patrimônio Histórico e Artístico Nacional, Museu Imperial, 2006.

KLÜPPEL, G. P.; SANTANA, M. C. de. Manual de conservação preventiva para edificações. Minc - IPHAN UCG,2010.

FIGUEIREDO, M. D. Valorização do Sistema Construtivo do Patrimônio Edificado. Universidade de Aveiro, Portugal, 2014.

LEI MUNICIPAL No 3.715/2006. Plano Diretor do Município de Taquara, RS.

LOURENÇO, P. B.; Conservation of cultural heritage buildings: Methodology and application to case studies Revista ALCONPAT, Volume 3, Número 2, Maio-Agosto 2013.

MESQUITA, E. F. T.; Caracterização, avaliação e recuperação estrutural de construções históricas, ALCONPATBoletim técnico 11, Mérida, México, 2015.

OLIVEIRA, C. A. P. Educação patrimonial no IPHAN. (CGE/DFR/ENAP, Gestão Pública, 2011) Monografia de Especialização - Escola Nacional de Administração Pública. Diretoria de Formação Profissional, Brasília, DF, 2011.

RESENDE, F. de S. Processos preventivos e corretivos no tratamento da umidade em construções.Dissertação (Mestrado em Engenharia Civil): Universidade Estadual de Campinas, Campinas/SP, 2000.

ROSIN, J. A. R. G. Vulnerabilidade da Preservação do Patrimônio Urbano: Estudo de Caso - Tupã. ANAP Brasil, v. 5, p. 65-86, 2012.

SANTOS, M. W. L. C. et al. Incidência de manifestações patológicas em edificações históricas de Sobral - CE. João Pessoa: Anais do IX congresso internacional sobre patologias e recuperação de estruturas - CINPAR, 2013.

SILVA, A. F. et al. Humidades nos edifícios tipos de intervenções necessárias. Universidade do Porto - FEUP (Faculdade de engenharia), 2012. 
SILVA, C. Prefeitura Municipal de Taquara. Disponível em:

<http://www.taquara.rs.gov.br/?titulo=Not\%EDcias\&template=conteudo\&categoria=817\&codigoCategoria=817\&idCo nteudo=2712\&idNoticia=8159\&tipoConteudo=INCLUDE_MOSTRA_NOTICIAS $>$. Acesso em: 18 set. 2019.

SCHÖNARDIE, C. E. Análise e tratamento das manifestações patológicas por infiltração em edificações. UNIJUÍ/DeTec, Ijuí, 2009.

SOUZA, M. F. Patologias ocasionadas pela umidade nas edificações. Belo Horizonte: UFMG, 2008.

STOLZ, C. M. et al. Levantamento das manifestações patológicas da fachada e análise dos diferentes revestimentos de argamassa quanto ao traço original e presença de contaminação por sais da futura pinacoteca municipal de Porto Alegre/RS- Universidade Federal do Rio Grande do Sul (UFRGS), Porto Alegre/RS, 2009.

TORRES A. S. e SILVA J. N. Patologias nos sistemas construtivos das edificações do início do século XX no sul do Rio Grande do Sul - estudo de caso de residência na cidade de rio grande/RS. REEC - Revista eletrônica de engenharia civil, vol. 10, $\mathrm{n}^{\circ} 1,39-55,2015$.

WILIMZING, M.et al. Projeto Cultural de Revitalização da C.V. Taquara, RS, 2014. 